\title{
Reflections from the Introduction of Blogs and RSS Feeds Into a Preservice Instructional Technology Course
}

\author{
Bruce Gabbitas \\ bruceg@byu.net \\ Charles R. Graham \\ charles.graham@byu.edu \\ Richard E. West \\ rw@byu.edu
}

Geoffrey Wright

Follow this and additional works at: https://scholarsarchive.byu.edu/facpub

Part of the Educational Psychology Commons

\section{Original Publication Citation}

West, R. E., Wright, G. W., Gabbitas, B., \& Graham, C. R. (26). Reflections from the Introduction of Blogs and RSS Feeds Into a Preservice Instructional Technology Course. TechTrends. 5(4). 54-6.

\section{BYU ScholarsArchive Citation}

Gabbitas, Bruce; Graham, Charles R.; West, Richard E.; and Wright, Geoffrey, "Reflections from the Introduction of Blogs and RSS Feeds Into a Preservice Instructional Technology Course" (2006). Faculty Publications. 980.

https://scholarsarchive.byu.edu/facpub/980

This Peer-Reviewed Article is brought to you for free and open access by BYU ScholarsArchive. It has been accepted for inclusion in Faculty Publications by an authorized administrator of BYU ScholarsArchive. For more information, please contact ellen_amatangelo@byu.edu. 


\author{
Reflections from the Introduction of Blogs and RSS Feeds \\ Into a Preservice Instructional Technology Course
}

\author{
Richard E. West \\ University of Georgia \\ Geoff Wright \\ Bruce Gabbitas \\ Charles R. Graham \\ Brigham Young University
}

Published Source: West, R. E., Wright, G. W., Gabbitas, B., \& Graham, C. R. (2006).

Reflections from the Introduction of Blogs and RSS Feeds Into a Preservice Instructional Technology Course. TechTrends. 50(4). 54-60.

$\begin{array}{cccc}\text { Richard E. West } & \text { Geoff Wright } & \text { Bruce Gabbitas } & \text { Charles R. Graham } \\ \text { 611 Aderhold Hall } & \text { 150 McKay } & \text { 150 McKay } & \text { 150-F McKay } \\ \text { University of Georgia } & \text { BYU } & \text { BYU } & \text { BYU } \\ \text { (706) 621-7825 } & (801) \text { 358-2832 } & \text { (801) 422-5097 } & \text { (801) 422-4110 } \\ \begin{array}{c}\text { (706) 542-4032 (fax) } \\ \text { rickwest@uga.edu }\end{array} & \begin{array}{c}\text { gei) 422-0314 (fax) } \\ \text { geoffwright@byu.edu }\end{array} & \begin{array}{c}\text { (801) 422-0314 (fax) } \\ \text { brucegabbitas@byu.edu }\end{array} & \begin{array}{c}\text { (801) 422-0314 (fax) } \\ \text { charles_graham@byu.edu }\end{array}\end{array}$


REFLECTIONS FROM USING BLOGS

\section{Abstract}

In this paper we report our experiences using blogs and RSS technology to teach over 800 preservice students in an introductory instructional technology course over the course of three semesters. Our main purpose for using blogs and RSS feeds was to promote critical reflection, student collaboration, and professional development. Through focus group interviews and class surveys, we discovered both effective and ineffective methods for integrating blogs and RSS feeds into a course. This paper will reflect on these findings and provide practical ideas for overcoming the challenges we faced in implementing blogs and RSS feeds as effective teaching and learning tools. 
REFLECTIONS FROM USING BLOGS

Reflections from the Introduction of Blogs and RSS Feeds

Into a Preservice Instructional Technology Course

Reflection and professional development are two key characteristics of an effective teacher that are frequently overlooked in preservice training (Halen-Faber, 1997; Patrick \& Reinhartz, 1999; Bowles, 2003). Darling-Hammond and McLaughlin found that, "Teachers learn by doing, reading, and reflecting (just as students do); by collaborating with other teachers; by looking closely at students and their work; and by sharing what they see" (1995, p. 599). The process of reflecting on one's practice and sharing what has been experienced are two integral aspects for substantive school improvement (Eaker, Richard and Rebecca DuFour, 2002). Anne Freese discovered in her research that reflection and professional development helped improve instructors' teaching practices and their students' learning (Freese, 1999).

Reflection can be defined as the type of thinking that serves to challenge notions of prior learning (Halen-Faber, 1997), and professional development can be defined by the actions teachers take to improve the quality of their teacher practices and knowledge. Dorph, Stodolsky, and Wohl (2002) suggest that for teachers to be active participants of professional development they "need to adopt more encompassing goals, expand their pedagogical repertoires, be more sensitive to the specific contexts in which they work, develop ways to promote learning among teachers as part of a social group, not only as individuals, and decipher how to challenge current practice and support change.”

Several technologies and methods have been utilized to assist teachers in reflecting and becoming involved in professional development. Two newer technologies used for these purposes are blogs and RSS feeds. Blogs and RSS feeds have grown in use tremendously in the 


\section{REFLECTIONS FROM USING BLOGS}

last five years. Blogs can potentially change how information is shared by allowing communities

to form, disperse information, and comment to each other in an easy-to-use environment via the

Internet. Blogs are now influencing many aspects of our society, from politics (such as in the

Howard Dean campaign), to news reporting (for example, first-hand reports from disaster sites), $\underline{\text { to niche communities (as in the many technical communities sharing specialized information }}$

through the use of RSS). Educators are also eager to see how blogs can impact learning. In this

paper we describe our experiences using blogs and RSS feeds with undergraduate preservice teachers. We discuss what did work, what didn't work, and how we would change our approach in the future to be more successful. The intent of the paper is to share ideas that will help others who are interested in or trying to use blogs in their own classes.

\section{Background of Blogs}

Blog is the common word to describe a weblog, or a website where people post thoughts and information about news or topics of interest. They were designed to provide a simple way for individuals to post ideas to the Internet, providing the opportunity and function for others to read and post comments on the site (Hernandez, 2004). One of the reasons for blogs' rapid increase in popularity is that limited technical knowledge about HTML or other webpage authoring tools are required (Godwin-Jones, 2003; Martindale \& Wiley, 2005). New blogging tools make it possible for anyone to easily build and edit their own personal blog site. Publishing becomes immediately accessible to anyone with an Internet connection. This added accessibility has been called the democratization of web publishing (Oatman, 2005). Another advantage derived from blogs is that publishing is no longer driven by profits and audience size. Blogs make it inexpensive and realistic to publish for small or niche audiences (Martindale and Wiley, 2005). Another of the advantages of blogs is that professionals can contribute to and learn from a 
REFLECTIONS FROM USING BLOGS

community of people with similar interests. Block (2001) suggests that many people who keep

blogs do it as a way of serving their community by sharing ideas and information.

Current Practices and Ideas for Using Blogs

Educators are exploring many possibilities for using blogs with students. Teachers use blogs to promote conversations about topics and experiences in school, and to post highlights from the class and the work of the students. Oatman (2005) reports that at Magnolia Elementary School in Joppa, Maryland ${ }_{2}$ fourth-grade students have built a blog-based website full of facts and trivia about their state. Other teachers have used blogs because they believed the tool could be used to help students reflect and read more on what they are learning. Poling (2005) wrote, "Blogging as a classroom application allows for enhanced comprehension and communication among students as well as the ability to build deeper understanding across the curriculum.... Blogging is a wonderful way to enhance student understanding” (Poling, p. 12).

Blogs have also been used in classrooms because teachers feel they promote literacy in the classroom (Huffaker, 2004), and because they are a great way to support dynamic learning, where students, parents, and teachers meet to read, discuss, and evaluate ideas and topics concerning learning and achievement. Teachers believe blogs can accomplish this measure because they are a place to develop ideas and invite feedback, and therefore motivate students to write and reflect more (lyde, 2005). Some second-language teachers believe that blogs can be used to give students authentic language activities (Godwin-Jones, 2003).

\section{Instructional Context and Methods}

Because we felt that it was important for preservice teachers to learn about technologies that can help them be reflective, and more connected and informed in their professional development, we began experimenting with blogs and RSS feeds in the fall semester of 2004. 
REFLECTIONS FROM USING BLOGS

We teach the instructional technology for teachers course in our university's preservice program.

This is a one- (for secondary education) or two-credits (for elementary education) required course for most preservice teachers. The class focus is not on teaching technology skills, but on learning and applying appropriate technology integration principles to specific teaching situations. The assignments typically are project-based tasks situated in teaching scenarios and completed in groups.

When we were considering technologies for helping teachers in this course improve their personal reflection, professional development, and collaboration habits, we decided to use blogs and RSS feeds because these technologies are free and relatively easy-to-use tools that could be implemented by practicing teachers with, or without, a very strong technology budget. The tools we implemented were Blogger (http://www.blogger.com) for composing a weblog and Bloglines (http://www.bloglines.com) for reading RSS feeds. Both are free, independently hosted, tools that are popular for beginning bloggers. Blogger can also be enhanced through plugins that allow for trackbacks and the posting of photos from sites like Flickr (http://www.flickr.com).

First semester —individual blogs and blogging buddies. We used the blogging tools differently for each of the first two semesters of this project. In the first semester when we began exploring blogging, we divided the students into "blogging buddies," which were groups of about six students. Because the classes were large (usually about forty to fifty students), each student was only required to read the blogs of his/her "blogging buddies," as well as the instructor. Throughout the semester, the instructor posted class announcements, answered common questions, directed the students to outside resources, and discussed class topics on the instructor blog. Because we believed that blogs, by nature, are meant to be less constrained by rules and standards, the students were not given rigid requirements for their own blogging. There 


\section{REFLECTIONS FROM USING BLOGS}

were some points given for blog participation, but the students were generally allowed to choose when to blog, how long to blog, and which posts to comment on. To encourage more reflective blogging and to create the feeling that the instructor was reading all of the blogs (which he could not do regularly), one instructor scanned the class blogs each week and selected two or three interesting posts to highlight—with commentary_ on the instructor's blog. This brought several conversations back to the forefront of the entire class for discussion. Our assessment at the end of this semester of the students' blogs was a subjective analysis by each instructor of how often the students posted and how thoughtful and reflective the posts were, according to the judgment of each individual instructor.

At the end of the semester, we surveyed all of the students from the four sections of the course $(n=86)$. Overall, we found that most students somewhat enjoyed using blogs that semester, and considered them to be helpful tools for stimulating reflection and discussion. Over two-thirds of the students felt that the technologies were easy to use. However, we found that there were some challenges encountered during the semester. Both students and instructors struggled with learning the new technologies and understanding how to use them effectively. The instructors felt that most students neglected their blogs and were not posting regularly or responding to their peers. This decreased the level of the discussion about class topics, and frustrated many students who felt nobody was reading their work. In group interviews and openended survey questions, a popular answer to whether blogs were effective tools was, "Theoretically, yes"-meaning that the students acknowledged that the technologies could be used effectively, but that it did not always happen that way in class.

As teachers, we felt that there were several things that contributed to the lack of truly reflective blogging and discourse during this first semester. First, even though blogs are meant to 


\section{REFLECTIONS FROM USING BLOGS}

be free expressions of a person's individuality, because the technology is new, the students seemed to need more structure in the assignments. Second, even though most students caught on to the tools, many did not. Because the tools were easy for us, we did not realize that they were not always easy for the students to learn. Most importantly, we neglected to teach the conceptual basis of the tools - how they differ from other online tools — and consequently, many students struggled to see how blogs were different from discussion boards, static websites, or even email. Finally, we found that monitoring and assessing 50 individual student blogs each semester was challenging — and this discouraged the teaching assistants in the course, who then were less supportive of the blogs in front of the students.

Second semester-group blogs and emphasis on RSS feeds. In the second semester of using blogs, we changed our methodologies somewhat in order to account for the challenges of the previous semester, as well as to encourage more than just reflection on class topics. In this semester, we put more emphasis on requiring students to find RSS feeds related to their subject and to post comments about things they learned from their feeds. The students also maintained group blogs instead of individual blogs, with about six students sharing ownership of each blog. Thus, for each course there would be an English blog, a science blog, etc., contributed to by all of the English or science students in that course. The instructor was also added as a group member for each blog and could participate in the conversations on occasion.

In the surveys at the end of the second semester, we found that student satisfaction had remained high for most students. However, a much larger percentage of students said that it was difficult to learn the technologies, which we feel is probably because we emphasized finding RSS feeds to read and report on in this semester, and it was hard to find very useful RSS feeds for some subjects (such as home economics, health, dance, etc.). The students also indicated that 
REFLECTIONS FROM USING BLOGS

they did not feel the technologies enhanced their interactions with each other. From interviews with the students, we learned that the students felt interacting through blogs was difficult because 1) they were not motivated to respond to each other because they only received credit for making original posts; 2) the students were often in the same cohort and had several classes together, so it was more efficient to just chat in the halls outside of class than respond on a blog; and 3) many students did not understand very well how to use an aggregator, and did not have any other feeds to read except the ones for the class. Because of this, they often decided not to use an aggregator at all. It seems that the technologies would perhaps be more useful as community-building tools if more time was taken to ensure students understood how to use the tools, and if the students were more separated from each other, perhaps during student teaching or after graduation. Guidelines For Improving Pedagogy With blogs and RSS

Overall, it seems that it was useful and helpful to integrate blogs and RSS feeds into our preservice course. However, through our experience we noticed several barriers that need to be resolved before the students are able to effectively use the tools. The remainder of this article will focus on our ideas for overcoming these barriers. These suggestions relate to work done before the semester begins (preparation), soon after it begins (technical learning curve), and throughout the rest of the semester (conceptual learning curve, see Figure 1).

Insert Figure 1 about here

Preparing for the semester. We discovered that before a class begins, the instructor needs to develop a well-defined purpose for using any new technologies, such as blogs and RSS feeds. It is easy to be lured into wanting to use blogs simply because they are a new, popular 
REFLECTIONS FROM USING BLOGS

technology while failing to have a clear purpose for their use. While we feel blogs can be used effectively for reflection, professional development, and collaboration, it may be helpful for instructors to decide before a semester begins which of these is their primary purpose, and then structure the assignments and activities to take advantage of the affordances the technologies provide. There are a variety of features available that are unique to the blogging world: trackback features, permalinks, archived posts, and blogrolls, for example. If the purpose for using blogs and RSS in the course is individual reflection, then promoting the use of trackbacks and comments is not as important, but helping students learn how to personalize their blog to express their individuality might be. On the other hand, if communication and sharing ideas are the primary purposes, then students need to be taught how to use these features, as well as the permalinks for referencing specific posts and how to use blogrolls to communicate a good URL to an audience.

Overcoming the technical barrier. Before we started implementing blogs and RSS feeds, we knew the technical aspect might create issues for a few students. In an effort to remedy this we focused the first week of the semester on instructing the students about the various technical aspects of the tools, how to set up a blog, subscribe to an RSS feed, post comments, etc. What we did not anticipate was how difficult and challenging this was for a large portion of the students. We had made the assumption that most of the students would be able to easily adopt these tools because each student was required to have fulfilled several technology prerequisites before enrolling in the class. However, we learned that blogging tools are still so new that they can be a challenge for students at first (at least, they were still relatively new when this project was undertaken - in fall of 2004). This is further complicated by the fact that the blogging tools we used are not well integrated and so students needed to use several different websites to read 
REFLECTIONS FROM USING BLOGS

blogs and compose their own blog posts. Some of the students became lost and confused because of this, and many said that simply being bombarded with too many new terms like "blogging," "aggregators," "RSS," "Atom," etc. in the first class period was intimidating. One student expressed this frustration by saying, "I think they (the instructors) tried to expose us to too much technology at one time ... [I] can only learn so much at a time." Another student mentioned, “The class moved so fast that I didn't know whether to try and follow along, or just sit and listen."

Upon reflection, we feel that there are a few methods we could have used to ease the technical barrier for students. First, we could provide more structure in the assignments, at least at first, and then steadily fade to allow students' individuality to bloom. For example, it would probably be easier for the students if we required them to post on their blog frequently the first couple of weeks, perhaps on topics provided by the instructor, until it is apparent that everyone understands how to blog. An example would be to have the students reflect on a main idea presented each day in class, asking for 1) what was taught; 2) what they learned; and 3) how it could be applicable to them. After it is apparent that the students understand how to post on their blog, the idea of subscribing to RSS feeds could then be introduced, and the students could be asked to read two articles from a teacher defined RSS feed, and then post a reflection on their blog summarizing what they read, learned, and how it could impact their teaching practices. Then the assignment could be relaxed to allow students to post about things they learn from their own RSS feeds. Once it seems everyone has mastered how to read their feeds, the assignment could be opened up even more to allow the students to post on their blogs about anything they hear or read about on the Internet or in their other classes. 
REFLECTIONS FROM USING BLOGS

Another idea for helping students with the technical challenges of blogging is to try and use simple tools, when possible. This was the main reason why we decided to use Blogger and Bloglines - because these are free, simple services that the preservice teachers should be able to easily access, set up on their own, and later use in their teaching. However, even these tools proved to have limitations that frustrated and confused many of the students. A newer option that may be helpful is to use Wordpress blogs from http://edublogs.org. WordPress is a blogging software that is more adaptable and flexible than Blogger blogs, and this website allows for free hosting and use of this software. It would probably also simplify the aggregating process for students if we taught those who have their own computers to use browsers such as Firefox or Safari as aggregators so they do not need to log in or download anything extra for reading their RSS feeds.

An additional aspect of the technology barrier that frustrated the students was the need to check various websites for class assignments, updates, communications from the instructor, etc. Many of the students complained that there were too many class-associated websites. For example, they were required to check the instructor's blog, several of their classmates' blogs, their Bloglines aggregator, the class's Blackboard site that was used for posting paper documents, and the class website for information about assignments. One student explained, "To be honest, I can't remember how to access RSS feeds, or how to find the ones I had located before; I kept getting confused on where I needed to go, was it to my blog, Bloglines, [or] the class website?" We realized that we could simplify things for our students by minimizing these other online distractions and by using our instructors' blogs for all class management issues when possible. This would also model an example of how a blog could be used as a free, accessible class management technology. 
REFLECTIONS FROM USING BLOGS

Overcoming the conceptual learning curve. We made the mistake originally of thinking that once the preservice teachers understood the technical aspects of the tools, they would easily understand how these tools differed from other online technologies, and consequently how they could be uniquely used to support educational goals. However, we were surprised to learn that by the end of the semester, many of the students knew how to blog and check their news readers, but they still did not understand how these tools were different from other technologies such as discussion boards, static (non-RSS) websites, and even email. Students knew how to use the tools, but did not understand how to apply the tools to achieve their learning goals.

This lack of comprehension about how blogging tools were unique caused many students to struggle in understanding how to integrate the tools into their future teaching. One student said, "The technology is useful, but how does this apply to us as teachers?" Another student also wondered, "I don't see how it's applicable in the classroom—-for me, in my area." Even when students did feel they might use the tools as teachers, their ideas of how to apply them were very narrow-usually only to communicate with other teachers. As instructors, we feel that if we could be more successful in teaching the concepts behind the tools, the students will be better able to evaluate the technologies and find ways to apply them to their own teaching.

One idea for helping students with the conceptual barriers might be to re-evaluate how much they understand about the technologies several weeks into the semester, and then help them get "back on track" if needed. We found that in the first couple of weeks in a semester, the students focused on understanding the technical aspects of how to set up and use the tools. Because the anxiety over how to technically complete the assignments became their top priority, they did not attend to nor understand our initial discussions about the concepts behind the tools. It seems it would be helpful to go back to discussing the concepts behind blogging and reading 


\section{REFLECTIONS FROM USING BLOGS}

RSS feeds after the students have overcome the technical barriers and are more able to learn and understand why they are doing these assignments, how the tools could be valuable, and what the purpose for the tools could be in their future teaching experiences.

It also seems that it would be helpful for instructors to model effective blogging for students so they can understand how the tools all tie together. By discussing all class assignments and announcements through the instructor's blog, the students are forced to read their RSS feeds - even if only to see what the instructor is writing. Consequently, they then might be more likely to read their other feeds as well. We believe it is probably also crucial for the instructor to exemplify the kind of thoughtful, reflective blogging that is expected from the students because many of them are new to blogging and the idea of writing for an audience as wide as the world wide web is daunting, and they need to see how more experienced bloggers integrate what they are learning into what they are writing through tracking back, citing sources, quoting material, and adding commentary.

In modeling how to blog, we feel we should participate more in responding to students' blog entries. This might encourage more students to comment and reply to each other. This was a challenge for us because some of our classes have up to 50 students, and it is impossible to provide thoughtful feedback to everything that is written on the students' blogs. However, one technique we used successfully is to scan through the posts of the week, and select two or three that seem especially thoughtful, and then highlight and track back to these on the instructor's blog with commentary from the instructor. This shows the class that the instructor is reading and participating in the class discussion, and it also brings more exemplary posts onto the main class blog to act as further models of good blogging for other students. 
REFLECTIONS FROM USING BLOGS

As we observed students struggling to understand how blogging is different from other activities, we learned that blogging and using RSS feeds is a new way to read and write, and one that is difficult at first to learn for beginners. For example, one cannot read RSS feeds like they would read from a book or journal article. One of the authors of this article subscribes to over 130 different feeds, many providing several different posts each day. He has learned the skill of quickly scanning through feeds and headlines and recognizing what is important for him to read, and what is not. Reading RSS feeds is also a much more disjointed way to read as there are frequently links to other sources. There are also tacit concepts understood by seasoned bloggers about how to find and recognize valuable, and credible, RSS sources. Blogging also requires a different mindset for writing. Many students commented that they did not write very much on their blogs because they did not feel that they knew enough yet to do so, or had a piece of writing that was polished enough for others to read. However, frequent commuters in the blogosphere understand that blogging is not always about communicating well developed ideas, but rather ideas that are still being developed that might benefit from comments, communication with others, or just from the process of "getting it out there."

These tacit reading/writing skills specific to RSS feeds and blogs might be more easily learned if the skills were modeled and made explicit by instructors and other bloggers. This could perhaps be done through discussion, sharing ideas for how to use the tools effectively, and by pointing the students to good examples of blogs that exemplify the writing process. The instructor could also structure activities that require students to find pieces of information from a list of RSS feeds in a way that will help them practice skimming and following hyperlinks. Another idea is to involve the students in a class activity where they read a thoughtful post from a popular blogger, search through their RSS feeds to find material for a possible reply, and 
REFLECTIONS FROM USING BLOGS

compose, in groups, replies to this post. After choosing one group's composition to represent the class, the reply could be posted as a comment to the original blog, and the students could wait to see if it draws out more discussion from the blog's owner. In this way, the students can see the entire process of reading, reflecting, and discussion from beginning to end.

\section{Conclusion}

Our journey these past few semesters into the blogosphere has had its ups and downs, and we feel we better understand now how students perceive these tools, and what kinds of barriers they will encounter when they use them for the first time. The ideas we have presented in this paper might provide some solutions to these barriers, but adjustments will need to be made continually as the tools for communicating in the read/write Internet continue to evolve almost every month - or even day. We encourage instructors and researchers to continue to move the dialogue past the novelty of these tools, and towards a solid collection of ideas for successfully using these, and other technologies associated with our rapidly changing information society. 
REFLECTIONS FROM USING BLOGS

\section{References}

Block, M. (2001). Communicating off the page. Library Journal, 126, 50-52.

Bowles, C. (2003). The Self-Expressed Professional Development Needs of Music Educators, Applications of Research in Music Education, 21(2), 1.

Clyde, L. A. (2005). Educational blogging. Teacher Librarians. 32(3): 43-45.

Darling-Hammond, L., \& McLaughlin, M. W. (1995). Policies that support professional development in an era of reform. Phi Delta Kappan, 76(8), 597-603.

Dorph, Gail Z., Stodolsky, Susan S., \& Wohl, Renee (2002). Growing as Teacher Educators:

Learning New Professional Development Practices. Journal of Jewish Education, 68(1), $58-72$.

Eaker, R., DuFour, R., \& Burnette, R. (2002). Getting Started: Reculturing Schools to Become Professional Learning Communities. Bloomington, Indiana: National Education Service.

Freese, Anne R. (1999). The role of reflection on preservice teachers' development in the context of a professional development school. Teaching and Teacher Education, 15(8), 898-909

Godwin-Jones, R. (2003). Blogs and wikis: Environments for on-line collaboration. Language Learning and Technology, 7, 12-16.

Halen-Faber, C. (1997). Encouraging Critical Reflection in Preservice Teacher Education: A Narrative of a Personal Learning Journey. New Directions for Adult and Continuing Education, 74(1), 51-60.

Hernandez, P. (2004). Blogs, threaded discussions accentuate constructivist teaching. Distance Education. 8(24): 4.

Huffaker, D. (2004). "The educated blogger: Using weblogs to promote literacy in the classroom. First Monday. Retrieved December 1, 2005 from http://www.firstmonday.org/issues/issue9_6/huffaker/\#author. 


\section{REFLECTIONS FROM USING BLOGS}

Martindale, T. \& Wiley, D. (2005). Using weblogs in scholarship and teaching. TechTrends, 49, $55-61$.

Patrick, D., \& Reinhartz, J. (1999). The Role of Collaboration in Teacher Preparation to Meet the Needs of Diversity. Education (Chula Vista, Calif.), 119(3), 388-99.

Poling, C. (2005). Blog on: Building communication and collaboration among staff and students. Learning and Leading with Technology. 32(6): 12-15.

Oatman, E. (2005). Blogomania! School Library Journal, 51, 36-39. 


\section{REFLECTIONS FROM USING BLOGS}

Figure Title and Caption

Title: Figure 1. A representation of three barriers to using blogs and RSS feeds.

Caption: From our experiences in using blogs and RSS feeds, we found three barriers to using these tools effectively and offer these ideas for overcoming the challenges we faced. These challenges were related to work done before the semester begins (preparation), soon after it begins when students (technical learning curve), and throughout the rest of the semester (conceptual learning curve). 